\title{
Lack of nutrient declarations and low nutritional quality of pre-packaged foods sold in Guatemalan supermarkets
}

\author{
Amarilys Alarcon-Calderon ${ }^{\top} \odot$, Stefanie Vandevijvere ${ }^{2}$, Manuel Ramírez-Zea ${ }^{1}$ and \\ Maria F Kroker-Lobos ${ }^{1, *}$ \\ 'INCAP Research Center for the Prevention of Chronic Diseases, Institute of Nutrition of Central America and Panama, \\ Guatemala City, Guatemala: ${ }^{2}$ School of Population Health, Department of Epidemiology and Biostatistics, \\ The University of Auckland, Auckland, New Zealand
}

Submitted 30 May 2019: Final revision received 17 January 2020: Accepted 23 January 2020: First published online 26 May 2020

\begin{abstract}
Objective: To assess the presence of nutrition declarations and nutritional quality in pre-packaged food products sold in Guatemala.

Design: We photographed nutrition labels of pre-packaged foods. We extracted information about declaration of energy, total/saturated/trans-fats, total/added sugars and $\mathrm{Na}$ content (critical nutrients). We classified all products according to their degree of processing (NOVA classification) and nutritional quality (PAHO and WHO-Europe nutrient profile models).

Setting: Pre-packaged foods for sale in seven supermarkets in Guatemala City. Participants: This study did not involve human subjects.

Results: We assessed 3459 pre-packaged foods, including $80 \%$ ultra-processed, $7 \%$ processed and $13 \%$ unprocessed/minimally processed foods or culinary ingredients. Nutritional information was available in 3021 products $(87.3 \%)$. Energy content was declared in $87.0 \%$; total fats in $86.1 \%$; saturated fats in $81.5 \%$; trans-fats in $48.9 \%$; total sugars in $70.3 \%$; added sugars in $0.5 \%$ and $\mathrm{Na} / \mathrm{salt}$ in $85.5 \%$ of products. Insufficient nutrient information made impossible to assess nutritional quality in 36.6 and $17.1 \%$ of products with the PAHO and WHOEurope models, respectively. Using PAHO and WHO nutrient profiles, we found that 66.2 and $50 \%$ of food products did not meet the model's nutritional criteria. Conclusions: A high proportion of pre-packaged foods with nutritional information available in Guatemalan supermarkets do not meet the nutritional criteria recommended by WHO and PAHO. Furthermore, a high proportion of products did not declare critical nutrients and many did not even provide any nutritional information. National regulations should consider making critical nutrient declarations (including trans-fats and sugars) mandatory for all products.
\end{abstract}

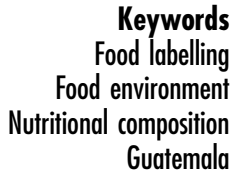

Keywords
Food labelling

Food environment Guatemala
Non-communicable diseases (NCD) are responsible for $70 \%$ of all deaths worldwide ${ }^{(1)}$. The majority of premature deaths occur in developing countries, which are going through a nutrition transition characterised by soaring rates of obesity ${ }^{(2-6)}$. Obesity and NCD are largely attributed to a poor diet ${ }^{(7)}$ characterised by high intakes of ultra-processed food products, which are not only convenient, cheap and palatable but also energy-dense and with excessive content of critical nutrients such as saturated fats, sugars and $\mathrm{Na}^{(8)}$. As in many low-middle income countries, ultra-processed food sales have rapidly increased in Guatemala, where obesity is a growing public health problem, and the majority of deaths $(69 \%)$ are related to $\mathrm{NCD}^{(9)}$.
Dietary patterns are influenced by the food environment, including the nutritional information available on food labels ${ }^{(10)}$. Hence, it is important to assess the nutritional information available for consumers and the nutritional quality of food products. Food labels have shown to influence food choices and to promote healthier diets ${ }^{(11,12)}$. The Central American Technical Regulations - RTCA - for food and beverages labelling, created by the Central American Council of Ministers of Economic Integration, establish declarations of some critical nutrients, but only if manufacturers claim a nutritional or a health-related property ${ }^{(13)}$.

The Pan American Health Association (PAHO) and the WHO have proposed nutrient profiling models to assess 


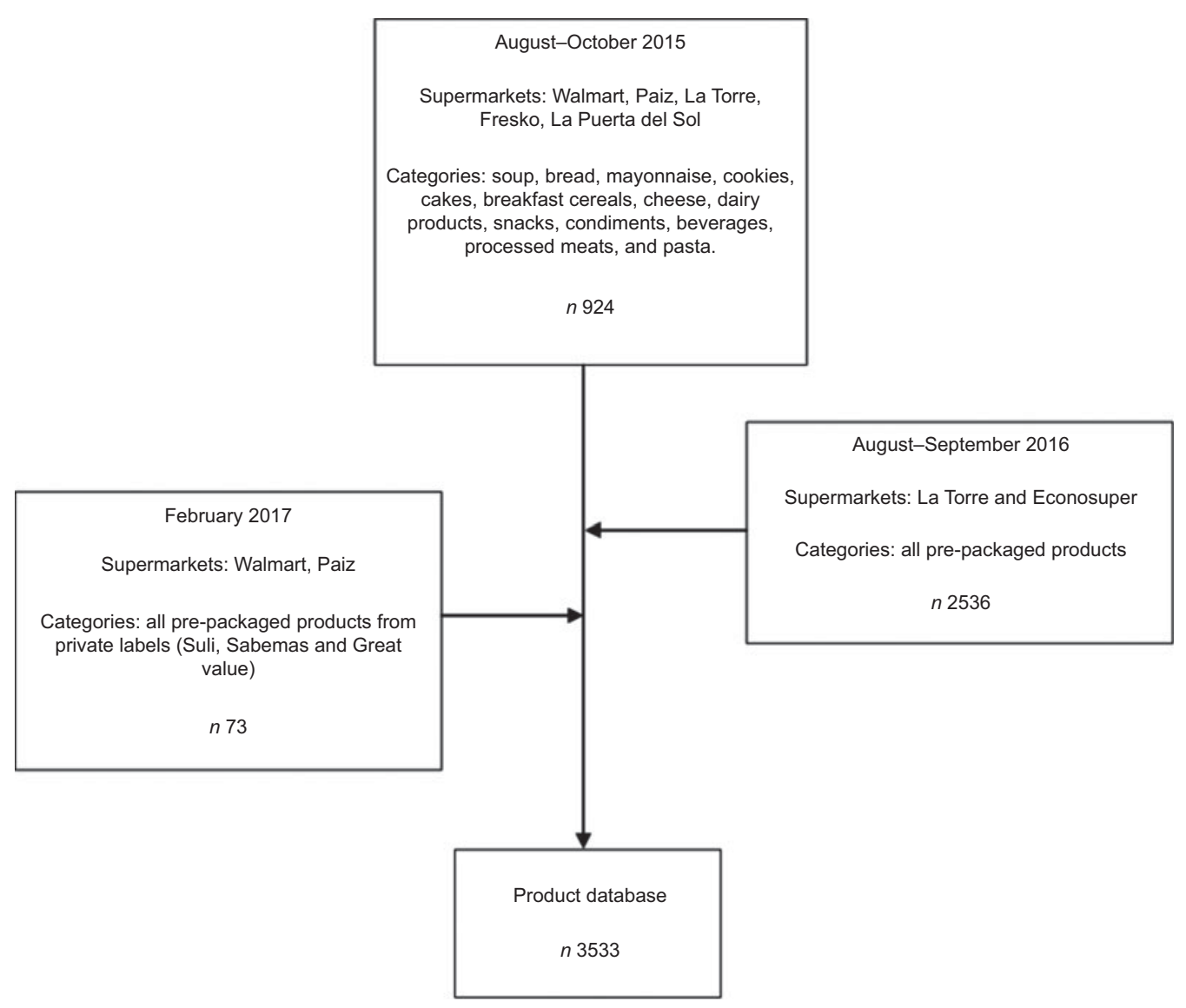

Fig. 1 Data collection periods, supermarkets and final sample size of photographed pre-packaged foods

the nutritional quality of food products and to guide member states to develop and implement public health programmes for reducing obesity and $\mathrm{NCD}^{(14,15)}$. These models take into consideration the nutritional composition with specific thresholds for critical nutrients. Nutrient profiling systems have been used to support public health initiatives, aiding consumers in selecting healthier options $^{(16,17)}$.

In Guatemala, unlike many high-income countries, nutrition facts label is still voluntary ${ }^{(13)}$. The proportion of processed and ultra-processed food products with adequate nutrition labelling and the nutritional quality (i.e. according to PAHO and WHO-European nutrient profiling models) of those products is currently unknown. Hence, the aim of this study was to assess, for the first time, the nutritional declarations on labels, the nutritional quality and the processing degree of pre-packaged foods sold in Guatemalan supermarkets.

\section{Methods}

\section{Data collection}

We adapted the data collection methodology proposed by the Food Monitoring Group ${ }^{(18,19)}$. We selected supermarkets in Guatemala, based on market share data by Euromonitor International $^{(20)}$, and data collection was carried out in three waves. In 2015, we photographed 924 products from the following categories: soup, bread, mayonnaise, cookies, cakes, breakfast cereals, cheese, dairy, snacks, condiments, beverages, processed meats and pasta. All products in these categories were photographed in the following supermarkets located in Guatemala City: Walmart, Paiz, La Torre, Maxibodega, Fresko and Puerta del Sol. In 2016, we photographed all available pre-packaged food products from La Torre and Econosuper, two distinct retail formats from the chain Unisuper ( $n$ 2536). In 2017, seventy-three Walmart private brand products (Suli ${ }^{\circledR}$, Sabemas ${ }^{\circledR}$ and Great Value ${ }^{\mathrm{TM}}$ ) were added to the sample. All products were purchased at the store, since Walmart did not allow taking pictures on-site (Fig. 1). All pre-packaged foods were photographed between August 2015 and January 2017. All photographs were taken by four research assistants. Illegible photographs were retaken. Products available in more than one retailer, different sizes or repeated products were entered into the database only once and with the most recent information. We excluded packages with multiple products, baby foods, infant formula, coffee, tea, spices and alcoholic beverages from both nutrient profiling analysis, as they are not contemplated in those models. 
Study data were entered in duplicate, using REDCap ${ }^{\mathrm{TM}}$ (Vanderbilt University), an electronic data capture tool ${ }^{(21)}$. Discrepancies were checked against the original photograph. We extracted nutritional information from labels, and two nutritionists categorised products separately. If there was disagreement, a third person was involved to reach consensus.

\section{Nutrient declarations, nutrient content and food labelling information}

Declaration and content for energy; total, saturated and trans-fats; total and added sugars; and salt/Na were extracted from nutrition facts label. We also extracted information on the manufacturing country, to differentiate Central American products. Central American products were defined as those manufactured in Guatemala, Belize, Honduras, El Salvador, Costa Rica, Nicaragua and Panama, as these countries follow the RTCA regulations.

When available, we also used the ingredient list to identify artificial sweeteners, additives and the ingredient list, to differentiate between processed and ultra-processed food $^{(14)}$.

\section{Food products classifications}

\section{NOVA classification}

Products were classified according to their processing degree using the NOVA food classification system groups: 1) unprocessed or minimally processed; 2) processed culinary ingredients; 3) processed and 4), ultra-processed products. A detailed description of this classification system is reported elsewhere ${ }^{(22,23)}$.

Pan American Health Association nutrient profile model This model classifies products as 'excessive in' if they exceed the following thresholds: total fats: $30 \%$ of total energy; saturated fats: $10 \%$ of total energy; trans-fats: $1 \%$ of total energy; Na: $1 \mathrm{mg}$ per energy; added sugars: $10 \%$ of total energy and sweeteners: any amount of artificial sweeteners. Free sugars were estimated with the method proposed by PAHO, based on total sugars and food group, taking into consideration if the products contain ingredients with natural sugars, such as fruit or milk ${ }^{(14)}$. Products with excessive content of at least one critical nutrient were considered as not meeting the model's nutritional criteria. The presence of artificial sweeteners was assessed from the ingredient list, when available. Since this model was created to assess the nutritional quality of processed and ultra-processed products, we considered products from NOVA groups 1 and 2 as meeting the nutritional criteria. As indicated by the PAHO nutrient profile, only products with declaration of energy, total, saturated and trans-fats; sugars, and salt/Na were included in this classification.
WHO-Europe nutrient profile model classification

We classified products into seventeen food groups, defined by the WHO-Europe nutrient profile model ${ }^{(15)}$. We created another group (Others) for products that did not fit into any category (e.g. condiments, vinegar, flavouring/colourant agents). The model defines specific thresholds for each food group in order to determine whether the content of energies, fats, $\mathrm{Na}$ and sugars meets $\mathrm{WHO}$ recommendations. The specific thresholds for each food group are described elsewhere ${ }^{(15)}$. Finally, the WHO-Europe nutrient profile classifies products into two groups, according to whether the food group meets nutritional criteria for advertising targeted to children. Confectionery, energy bars, cakes and sweets, juices, energy drinks and edible ices do not meet criteria to be advertised, whereas fresh and frozen meat, poultry, fish, fruit, vegetables and legumes automatically meet nutritional criteria. For other categories, if the product exceeds the specific thresholds, the product is classified as 'not meeting nutritional criteria'.

For classification purposes with PAHO and WHO systems, if a product had no specific declaration of saturated or trans-fats, but the label reported $0 \mathrm{~g}$ of total fats, it was considered as 'meeting nutritional criteria' in saturated/ trans-fats. The same approach was considered when total carbohydrates were $0 \mathrm{~g}$, but no declaration of total or added sugars was made.

\section{Data analysis}

We evaluated the proportion of foods declaring energy; total, saturated, and trans-fats; total and added sugars; and salt/Na (critical nutrients). Nutrient content was standardised to a portion of $100 \mathrm{~g}$ or $100 \mathrm{ml}$ (including beverages or products requiring reconstitution). We only analysed products with all information necessary for classification according to the PAHO and WHO-Europe nutrient profile systems.

We also calculated the median content of energy, total/ saturated/trans-fats, total/added sugars and $\mathrm{Na}$ and the proportion of unclassifiable products (e.g. the model was not applicable or information available on the package was not sufficient to classify the product by healthiness or processing degree). For both WHO and PAHO nutrient profile models, we calculated the proportion of products meeting and not meeting nutritional criteria and the overall proportion of processed or ultra-processed products (NOVA classification groups 3 and 4) not meeting the nutritional criteria for critical nutrients.

Finally, we compared nutrient declarations between Central American products and products manufactured elsewhere. We used $\chi^{2}$ tests to assess for differences between proportions, including $95 \%$ CI. We also used the Mann-Whitney $U$ test to compare nutritional content between products meeting/not meeting nutritional criteria. Analyses were conducted using STATA software version 13.0 (StataCorp LP). 
Table 1 Critical nutrient declaration on pre-packaged foods sold in supermarkets in Guatemala*

\begin{tabular}{|c|c|c|c|c|c|c|c|}
\hline Classification & $\begin{array}{l}\text { Energy } \\
(\%)\end{array}$ & $\begin{array}{l}\text { Total fats } \\
(\%)\end{array}$ & $\begin{array}{l}\text { Saturated fats } \\
(\%)\end{array}$ & $\begin{array}{l}\text { Trans-fats } \\
(\%)\end{array}$ & $\begin{array}{l}\text { Total sugars } \\
(\%)\end{array}$ & $\begin{array}{l}\text { Added sugars } \\
\qquad(\%)\end{array}$ & $\begin{array}{l}\mathrm{Na} \\
(\%)\end{array}$ \\
\hline \multicolumn{8}{|l|}{ By food group $†$} \\
\hline Confectionery ( $n$ 387) & $94 \cdot 8$ & $92 \cdot 5$ & 88.6 & $50 \cdot 4$ & $86 \cdot 8$ & 0.1 & $91 \cdot 2$ \\
\hline Cakes, sweet biscuits and pastries ( $n$ 253) & $93 \cdot 3$ & 93.3 & 91.7 & $70 \cdot 4$ & $82 \cdot 6$ & 0.0 & 92.5 \\
\hline Savoury snacks ( $n$ 289) & $89 \cdot 3$ & 88.9 & 85.5 & 67.5 & 72.7 & 0.0 & 88.9 \\
\hline Beverages ( $n 526)$ & $96 \cdot 6$ & $96 \cdot 4$ & 91.8 & 40.9 & $79 \cdot 1$ & 0.6 & $96 \cdot 6$ \\
\hline Edible ices ( $n$ 47) & 74.5 & 74.5 & $53 \cdot 2$ & $12 \cdot 8$ & 53.2 & 0.0 & 74.5 \\
\hline Breakfast cereals ( $n$ 182) & 98.4 & 98.4 & $90 \cdot \overline{7}$ & $58 \cdot 8$ & 91.8 & 0.0 & $96 \cdot 7$ \\
\hline Yoghurts, cream ( $n$ 135) & $97 \cdot 0$ & $96 \cdot 3$ & 94.8 & 21.5 & 83.7 & $10 \cdot 4$ & $95 \cdot 6$ \\
\hline Cheese ( $n$ 177) & $85 \cdot 3$ & 85.9 & 79.7 & $40 \cdot 1$ & 55.9 & 0.0 & $83 \cdot 6$ \\
\hline $\begin{array}{l}\text { Ready-made and convenience foods } \\
\text { ( }(n 151)\end{array}$ & $99 \cdot 3$ & $99 \cdot 3$ & $96 \cdot 7$ & $76 \cdot 2$ & $76 \cdot 2$ & 0.0 & $99 \cdot 3$ \\
\hline Butter and other fats and oils ( $n 111)$ & $97 \cdot 3$ & $96 \cdot 4$ & $96 \cdot 4$ & 73.0 & $60 \cdot 4$ & 0.0 & 95.5 \\
\hline $\begin{array}{l}\text { Bread, bread products and crisp breads } \\
\quad(n 104)\end{array}$ & $70 \cdot 2$ & $70 \cdot 2$ & $65 \cdot 4$ & $57 \cdot 7$ & $60 \cdot 6$ & 0.0 & $69 \cdot 2$ \\
\hline Pasta, rice and grains ( $n 110)$ & $97 \cdot 3$ & $90 \cdot 9$ & $85 \cdot 5$ & $45 \cdot 5$ & $58 \cdot 2$ & 0.0 & $90 \cdot 0$ \\
\hline Fresh and frozen meat, poultry, fish $(n 50)$ & $20 \cdot 0$ & $18 \cdot 0$ & $18 \cdot 0$ & 8.0 & $12 \cdot 0$ & 0.0 & $20 \cdot 0$ \\
\hline Processed meat, poultry, fish ( $n$ 261) & $55 \cdot 9$ & $56 \cdot 7$ & $53 \cdot 6$ & 29.5 & $31 \cdot 4$ & 0.0 & $54 \cdot 0$ \\
\hline $\begin{array}{l}\text { Fresh and frozen fruit, vegetables and } \\
\text { legumes }(n 58)\end{array}$ & $6 \cdot 9$ & $6 \cdot 9$ & $5 \cdot 2$ & 3.5 & $6 \cdot 9$ & 0.0 & 6.9 \\
\hline $\begin{array}{l}\text { Processed fruit, vegetables and legumes } \\
(n 270)\end{array}$ & $87 \cdot 8$ & $84 \cdot 1$ & $75 \cdot 9$ & $40 \cdot 0$ & 73.7 & 0.0 & $84 \cdot 4$ \\
\hline Sauces, dips and dressings ( $n$ 258) & $99 \cdot 2$ & $98 \cdot 5$ & $92 \cdot 3$ & $64 \cdot 7$ & $86 \cdot 1$ & 0.0 & $98 \cdot 8$ \\
\hline Other $(n 90)$ & 58.9 & 58.9 & $51 \cdot 1$ & $35 \cdot 6$ & $37 \cdot 8$ & 0.0 & $58 \cdot 9$ \\
\hline \multicolumn{8}{|l|}{ By processing degreeł } \\
\hline $\begin{array}{l}\text { Not processed/minimally processed } \\
(n \text { 355) }\end{array}$ & $61 \cdot 7$ & $56 \cdot 4$ & $51 \cdot 7$ & $25 \cdot 7$ & $39 \cdot 4$ & 0.0 & $57 \cdot 5$ \\
\hline Culinary ingredients $(n 66)$ & $86 \cdot 4$ & 84.9 & $80 \cdot 3$ & $60 \cdot 6$ & $45 \cdot 5$ & 0.0 & $81 \cdot 8$ \\
\hline Processed foods ( $n$ 242) & $86 \cdot 1$ & $85 \cdot 7$ & $79 \cdot 0$ & $43 \cdot 3$ & $66 \cdot 0$ & 0.0 & $84 \cdot 0$ \\
\hline Ultra-processed food products ( $n$ 2870) & $90 \cdot 3$ & $90 \cdot 0$ & $85 \cdot 6$ & $52 \cdot 1$ & $75 \cdot 2$ & 0.6 & $89 \cdot 3$ \\
\hline All packaged foods ( $n$ 3459) & $87 \cdot 0$ & $86 \cdot 1$ & 81.5 & 48.9 & $70 \cdot 3$ & 0.5 & 85.5 \\
\hline
\end{tabular}

*Percentages are the proportion of packaged food with nutrient declaration by each food group classification.

†Food groups classification based on the WHO/European nutrient profile model ${ }^{(15)}$.

†Level of processing: Not processed/minimally processed, culinary ingredients, processed foods and ultra-processed food groups were classified according to the NOVA food classification system ${ }^{(22,23)}$.

\section{Results}

We collected data for 3533 pre-packaged products. Seventy-four products were excluded due to wrong nutritional information (e.g. the amount of a single macronutrient or the sum of all three macronutrients exceeded the portion size), leaving 3459 products for analyses. The largest categories were beverages (15.2\%), confectionery (11.5\%) and savoury snacks (8.6\%). The number of products in each category ranged from 387 (beverages) to 47 (edible ices) (Table 1). Most products were classified as ultra-processed (80.9\%).

\section{Nutrient declarations}

We found that $12.7 \%$ of packaged products had no nutritional information. This proportion was higher for processed compared with ultra-processed foods (13.9 $v$. $9.5 \%, P=0.024)$. None of the food products declared any critical nutrient, while $72.0 \%$ of products declared five or six. Not processed/minimally processed products showed the least nutritional information, but few categories such as processed meats, bread and edible ices displayed little information too $(43.3,29.8$ and $25.5 \%$ had no declaration of any critical nutrient, respectively). The least declared critical nutrient on packages was added sugars (0.5\%), followed by trans-fats (48.9\%) and total sugars (70.3\%) (Table 1).

Products manufactured in Central America had fewer declarations of critical nutrients compared with products manufactured elsewhere. This was true for all critical nutrients $(P<0 \cdot 001)$ : energy (83.0 v. 94.1), total fats $(82 \cdot 0$ $v$. 93.3), saturated fats $(77.5 v .88 .8)$, trans fats $(43.4 v$. 58.9), total sugars (61.4 v. 86.2), added sugars ( $0.0 v .1 .5)$ and $\mathrm{Na}(82.0 v .91 \cdot 7)$.

\section{Content of critical nutrients}

The most energy-dense food groups were butter and oils (median of $3347.2 \mathrm{~kJ} / 100 \mathrm{~g}$ ), followed by snacks (2122.5432 kJ/100 g), and cakes and pastries (1781.1288 kJ/ $100 \mathrm{~g})$. Pre-packaged fresh fruit and vegetables were the least energy-dense foods $(143.5112 \mathrm{~kJ} / 100 \mathrm{~g})$. Although unprocessed/minimally processed foods had a median energy density of $1486.5752 \mathrm{~kJ} / 100 \mathrm{~g}$, when excluding pasta, rice and grains, the median value decreased to $572.3712 \mathrm{~kJ} /$ $100 \mathrm{~g}$. Culinary ingredients had a high proportion of oils $(74.5 \%)$, which explains the median energy density of 
$3514.56 \mathrm{~kJ} / 100 \mathrm{~g}$. Processed and ultra-processed products had median energy densities of 392.4592 and $1321.3072 \mathrm{~kJ} /$ $100 \mathrm{~g}$, respectively (Table 2). The levels of saturated fats per $100 \mathrm{~g}$ were the highest in butter and oils (18 g), cheese $(14.3 \mathrm{~g})$ and edible ices $(12.9 \mathrm{~g})$. Only $4 \%$ of products declared trans-fats, which explains the median level of $0 \mathrm{~g}$ in all food groups categories.

The highest levels of total sugars per $100 \mathrm{~g}$ were found in confectionery $(51.7 \mathrm{~g})$, cakes and pastries (26.3196 g) and breakfast cereals ( $24.3 \mathrm{~g}$ ). Added sugars could not be evaluated, since only eighteen products included such information on the label. The highest level of $\mathrm{Na}$ was found in processed foods $(395 \mathrm{mg})$. The category with the highest content of Na was 'others' $(8140.0 \mathrm{mg})$ which includes condiments, followed by ready-made/convenience foods (1037.7 mg).

Products that do not meet the PAHO nutritional criteria were higher in $\mathrm{Na}$ (median 343.7 v. $12.5 \mathrm{mg} / 100 \mathrm{~g}$, $P<0.0001$ ); total sugars (9.4 v. $1.1 \mathrm{~g} / 100 \mathrm{~g}, P<0.0001$ ); added sugars $(7.5 \mathrm{v} \cdot 0.0 \mathrm{~g} / 100 \mathrm{~g}, P<0.0001)$; saturated fats $(0.6 v \cdot 0.0 \mathrm{~g} / 100 \mathrm{~g}, P=0.0427)$ than those who meet criteria. We did not find a significant difference for total or trans-fats. With the WHO model, products not meeting criteria was also higher in $\mathrm{Na}(320.0 v .48 .0 \mathrm{mg} / 100 \mathrm{~g}$, $P<0.0001)$; total sugars $(10.5$ v. $0.8 \mathrm{~g} / 100 \mathrm{~g}, P<0.0001)$; added sugars $(7.1 v .0 .0 \mathrm{~g} / 100 \mathrm{~g}, P<0.0001)$; total fats $(6.3 v .2 .0 \mathrm{~g} / 100 \mathrm{~g}, P<0.0001)$ and saturated fats $(1.8 v$. $0.5 \mathrm{~g} / 100 \mathrm{~g}, P<0.0001)$. In relation to trans-fats, we found higher content in products that did not meet nutritional criteria, $(P=0 \cdot 0021)$, even though medians were 0 .

\section{Nutrient profiling systems}

From the 3459 products, 1266 (36.6\%) could not be assessed as meeting/not meeting criteria with the PAHO model because nutrient information was missing. Unprocessed/minimally processed foods and culinary ingredients ( $n$ 424) were considered to meet the model's criteria (Fig. 2). Of the ultra-processed and processed products with enough information to be classified ( $n$ 1769), $98.2 \%$ and $90.2 \%$ of products, respectively, did not meet the criteria for at least one critical nutrient (Table 3). Most products were excessive in $1-2$ (64.2\%) or $3-4$ (33.6\%) critical nutrients.

Sixty percentage of all processed and ultra-processed products did not meet the nutritional criteria for added sugars. All of the edible ices and most of the confectionery (91.7\%), beverages (90.9\%), breakfast cereals (88.6\%) and cakes, biscuits and pastries (74.7\%) were excessive in added sugars. Artificial sweeteners were present in $12.6 \%$ of products.

More than half of the products did not meet nutritional criteria for $\mathrm{Na}$, especially processed meat (100\%), cheese (95.4\%) and bread (93.2\%). The categories not meeting criteria for saturated fats were cheese $(95.4 \%)$, edible ices $(85.7 \%)$ and yoghurts and cream (85.2\%). Two percentage of the products had excessive amounts of trans-fats. The proportion was higher in cheese (9.2\%), cakes (7.5\%), yoghurts and cream (7.4\%), and butter/ oils (6.8\%).

With the WHO-Europe model, $592(17 \cdot 1 \%)$ did not have all the necessary information to be classified and 90 (2.6\%) did not fit any of the WHO categories and could not be evaluated. Per the model, products in few categories automatically did not meet nutritional criteria, such as confectionery, juices, energy drinks and edible ices. Products in two categories, fresh/frozen meat, poultry and fish ( $n$ 50) and fresh/frozen fruit, vegetables and legumes ( $n 58)$, were considered to meet criteria. Processed and ultra-processed products were evaluated using different thresholds for each category (Table 4). Overall, only $1.8 \%$ of ultra-processed and $9.8 \%$ of processed food products met nutritional criteria according to the PAHO model (Table 3). Based on the WHO-European model, $8 \%$ of ultra-processed products and $34 \%$ of processed food met the critical nutrients content limits (Table 4).

\section{Discussion}

Our main finding was the substantial lack of nutritional information available in pre-packaged food products available in Guatemalan supermarkets, particularly on critical nutrients related to chronic diseases such as total sugars and added sugars. Among products that did have nutritional information, a high proportion were excessive in critical nutrients.

Guatemala and other Central American countries share a regulation concerning nutrition facts label (the Central American Technical Regulation, RTCA) ${ }^{(13)}$. Despite the Codex Alimentarius Guidelines for Nutritional Labelling, manufacturers are not required to include nutrient declarations on labels of pre-packaged food products, except when labels also contain nutritional claims (any claim suggesting or implying that a product has special nutritional properties, describing the content of a specific nutrient, a nutrient's physiological function or the relationship with health or disease reduction) ${ }^{(13,24)}$. The lack of universal mandatory nutritional labelling explains the high proportion of processed and ultra-processed products without nutritional information.

The manufacturers who include nutrition facts label in their products are required to declare energy content, total/saturated fats, carbohydrates and protein content ${ }^{(13)}$. Despite the well-demonstrated association between obesity, NCD and mortality with high intake of sugars and fats, declaration is voluntary in Central America ${ }^{(25-27)}$. According to our findings, nutrients like sugars and trans-fats, the declaration of which is not mandatory, appeared in a smaller proportion on labels compared with those that are mandatory. Other studies in countries with voluntary declaration of nutrients have also showed low declaration frequencies ${ }^{(28,29)}$. Moreover, Central American products 
Table 2 Critical nutrient of pre-packaged foods sold in supermarkets in Guatemala (per $100 \mathrm{mg}$ or $100 \mathrm{ml})^{\star}$

\begin{tabular}{|c|c|c|c|c|c|c|c|c|c|c|c|c|c|c|}
\hline \multirow[b]{2}{*}{ Classification } & \multicolumn{2}{|c|}{ Energy (kJ) } & \multicolumn{2}{|c|}{ Total fat $(\mathrm{g})$} & \multicolumn{2}{|c|}{ Saturated fat (g) } & \multicolumn{2}{|c|}{ Trans-fat(g) } & \multicolumn{2}{|c|}{ Total sugar (g) } & \multicolumn{2}{|c|}{ Added sugar (g) } & \multicolumn{2}{|r|}{$\mathrm{Na}(\mathrm{mg})$} \\
\hline & Median & IQR & Median & IQR & Median & IQR & Median & IQR & Median & IQR & Median & IQR & Median & IQR \\
\hline \multicolumn{15}{|l|}{ By food group $\dagger$} \\
\hline Confectionery ( $n$ 387) & $1569 \cdot 0$ & $1255 \cdot 2,1952 \cdot 7$ & $2 \cdot 6$ & $0.0,21 \cdot 4$ & 1.4 & $0.0,9.4$ & 0.0 & $0.0,0.0$ & $51 \cdot 7$ & $25 \cdot 8,59 \cdot 9$ & - & - & 71.4 & $14 \cdot 3,175 \cdot 7$ \\
\hline $\begin{array}{l}\text { Cakes, sweet biscuits and } \\
\text { pastries ( } n \text { 253) }\end{array}$ & $1781 \cdot 1$ & $1548 \cdot 9,1969 \cdot 0$ & $14 \cdot 8$ & $8 \cdot 6,20 \cdot 0$ & $6 \cdot 0$ & $2 \cdot 6,9 \cdot 6$ & 0.0 & $0.0,0.0$ & $26 \cdot 3$ & $12 \cdot 7,35 \cdot 7$ & - & - & $350 \cdot 0$ & $196 \cdot 7,660 \cdot 7$ \\
\hline Savoury snacks ( $n$ 289) & $2122 \cdot 5$ & $1966 \cdot 5,3301 \cdot 2$ & $28 \cdot 2$ & $22 \cdot 5,35 \cdot 7$ & $7 \cdot 1$ & $3 \cdot 6,11 \cdot 6$ & 0.0 & $0.0,0.0$ & 0.6 & $0 \cdot 0,4 \cdot 1$ & - & - & $538 \cdot 6$ & $250 \cdot 0,845 \cdot 2$ \\
\hline Beverages $(n 526)$ & $215 \cdot 9$ & $146 \cdot 4,1292 \cdot 0$ & 0.0 & $0.0,1.8$ & 0.0 & $0.0,0.8$ & 0.0 & $0.0,0.0$ & $9 \cdot 8$ & $5 \cdot 5,21 \cdot 9$ & 3.0 & $3 \cdot 0,6 \cdot 0$ & 33.9 & $9 \cdot 2,121 \cdot 0$ \\
\hline Edible ices $(n 7)$ & $896 \cdot 2$ & $836 \cdot 8,976 \cdot 1$ & $12 \cdot 9$ & $10 \cdot 6,15 \cdot 6$ & $10 \cdot 0$ & $8 \cdot 3,10 \cdot 6$ & 0.0 & $0.0,0.0$ & $16 \cdot 5$ & $14 \cdot 1,16 \cdot 5$ & - & - & $69 \cdot 2$ & $47 \cdot 1,88 \cdot 2$ \\
\hline Breakfast cereals ( $n$ 182) & 1581.6 & $1534 \cdot 3,1673 \cdot 6$ & 4.7 & $1.8,6 \cdot 7$ & 0.0 & $0.0,1.5$ & 0.0 & $0.0,0.0$ & $24 \cdot 3$ & $5 \cdot 0,33 \cdot 3$ & - & - & $335 \cdot 0$ & $13 \cdot 8,472 \cdot 2$ \\
\hline Yoghurts, cream ( $n$ 135) & 397.5 & $335 \cdot 1,520 \cdot 1$ & 2.5 & $1.8,5.0$ & 1.3 & $1.0,2.6$ & 0.0 & $0.0,0.0$ & 11.3 & $4 \cdot 0,13 \cdot 9$ & $5 \cdot 2$ & $4 \cdot 0,10 \cdot 3$ & $45 \cdot 3$ & $40 \cdot 0,55 \cdot 0$ \\
\hline Cheese ( $n$ 177) & $1255 \cdot 2$ & $1046 \cdot 0,1494 \cdot 1$ & $22 \cdot 0$ & $18 \cdot 0,28 \cdot 6$ & $14 \cdot 3$ & $10 \cdot 0,17 \cdot 9$ & 0.0 & $0.0,0.0$ & $0 \cdot 0$ & $0.0,3 \cdot 6$ & - & - & 642.9 & $535 \cdot 7,900 \cdot 0$ \\
\hline $\begin{array}{l}\text { Ready-made and convenience } \\
\text { foods ( } n \text { 151) }\end{array}$ & $1394 \cdot 5$ & $871 \cdot 5,1569 \cdot 0$ & $4 \cdot 7$ & $1 \cdot 5,14 \cdot 7$ & $1 \cdot 1$ & $0 \cdot 0,6 \cdot 7$ & 0.0 & $0.0,0.0$ & 1.4 & $0.0,5 \cdot 0$ & - & - & $1037 \cdot 7$ & $442 \cdot 7,3242 \cdot 2$ \\
\hline $\begin{array}{l}\text { Butter and other fats and oils } \\
\quad(n 111)\end{array}$ & $3347 \cdot 2$ & $2390 \cdot 7,3586 \cdot 1$ & $81 \cdot 7$ & $64 \cdot 3,93 \cdot 3$ & $18 \cdot 0$ & $13 \cdot 0,32 \cdot 1$ & 0.0 & $0.0,0.0$ & 0.0 & $0.0,0.0$ & - & - & $9 \cdot 0$ & $0.0,714 \cdot 3$ \\
\hline $\begin{array}{l}\text { Bread, bread products and crisp } \\
\quad \text { breads }(n 104)\end{array}$ & $1181 \cdot 1$ & $1112 \cdot 5,1338 \cdot 9$ & $4 \cdot 6$ & $3 \cdot 4,7 \cdot 3$ & $1 \cdot 7$ & $1 \cdot 2,2 \cdot 7$ & 0.0 & $0.0,0.0$ & 4.5 & $2 \cdot 2,6 \cdot 0$ & - & - & $490 \cdot 3$ & $393 \cdot 6,581 \cdot 6$ \\
\hline Pasta, rice and grains ( $n 110)$ & $1521 \cdot 3$ & $1481 \cdot 1,1521 \cdot 3$ & 1.5 & $1 \cdot 0,1 \cdot 8$ & 0.2 & $0.0,0.4$ & 0.0 & $0.0,0.0$ & 1.8 & $0.0,3.5$ & - & - & 0.0 & $0.0,20 \cdot 9$ \\
\hline $\begin{array}{l}\text { Fresh and frozen meat, poultry } \\
\text { and fish }(n 50)\end{array}$ & 589.9 & $361 \cdot 9,658 \cdot 6$ & $6 \cdot 3$ & $5 \cdot 5,9 \cdot 3$ & $2 \cdot 2$ & $2,3.7$ & 0.0 & $0.0,0.0$ & 0.0 & $0.0,0.0$ & - & - & $301 \cdot 8$ & $113 \cdot 9,485 \cdot 6$ \\
\hline $\begin{array}{l}\text { Processed meat, poultry, fish } \\
\quad(n 261)\end{array}$ & $703 \cdot 3$ & $531 \cdot 4,912 \cdot 9$ & $9 \cdot 4$ & $3 \cdot 6,16 \cdot 0$ & 1,9 & $0.9,4.6$ & 0.0 & $0.0,0.0$ & 0.4 & $0.0,1.5$ & - & - & $608 \cdot 7$ & $392 \cdot 9,964 \cdot 3$ \\
\hline $\begin{array}{l}\text { Fresh and frozen fruit, vegetables } \\
\text { and legumes }(n 58)\end{array}$ & 143.5 & $100 \cdot 0,202 \cdot 1$ & 0.0 & $0.0,0.0$ & 0.0 & $0.0,0.0$ & 0.0 & $0.0,0.0$ & 3.5 & $0.0,8 \cdot 7$ & - & - & 0.0 & $0 \cdot 0,17 \cdot 7$ \\
\hline $\begin{array}{l}\text { Processed fruit, vegetables and } \\
\text { legumes }(n 270)\end{array}$ & $418 \cdot 4$ & $199 \cdot 2,732 \cdot 2$ & 0.0 & $0 \cdot 0,1 \cdot 3$ & 0.0 & $0.0,0.0$ & 0.0 & $0.0,0.0$ & $3 \cdot 3$ & $0.3,18 \cdot 0$ & - & - & $76 \cdot 9$ & $1 \cdot 9,476 \cdot 2$ \\
\hline $\begin{array}{l}\text { Sauces, dips and dressings } \\
(\text { ( } 258)\end{array}$ & $511 \cdot 7$ & $231 \cdot 8,1133 \cdot 0$ & $1 \cdot 3$ & $0 \cdot 0,20 \cdot 0$ & $0 \cdot 0$ & $0 \cdot 0,4 \cdot 2$ & $0 \cdot 0$ & $0.0,0.0$ & $5 \cdot 7$ & $1 \cdot 7,12 \cdot 5$ & - & - & $818 \cdot 2$ & $493 \cdot 3,1266 \cdot 7$ \\
\hline $\begin{array}{l}\text { Not processed/minimally } \\
\text { processed } \\
(n 335)\end{array}$ & $1486 \cdot 6$ & $422 \cdot 2,1527 \cdot 6$ & 1.8 & $0.9,3.6$ & 1.4 & $0.0,9 \cdot 4$ & $0 \cdot 0$ & $0.0,0.0$ & $1 \cdot 8$ & $0 \cdot 0,4 \cdot 2$ & - & - & 5 & $0 \cdot 0,39 \cdot 2$ \\
\hline Culinary ingredients $(n 66)$ & $3514 \cdot 6$ & $3108 \cdot 7,3705 \cdot 8$ & $93 \cdot 3$ & $82 \cdot 0,100 \cdot 0$ & $6 \cdot 0$ & $2 \cdot 6,9 \cdot 6$ & 0.0 & $0.0,0.0$ & 0.0 & $0.0,0.0$ & - & - & 0.0 & $0.0,0.0$ \\
\hline Processed foods ( $n$ 242) & 392.5 & $168 \cdot 6,1195 \cdot 4$ & 0.7 & $0.0,15 \cdot 9$ & $7 \cdot 1$ & $3 \cdot 6,11 \cdot 6$ & 0.0 & $0.0,0.0$ & $2 \cdot 4$ & $0.0,6 \cdot 4$ & - & - & $395 \cdot 0$ & $128 \cdot 3,639 \cdot 6$ \\
\hline $\begin{array}{l}\text { Ultra-processed food products } \\
\quad(n \text { 2870) }\end{array}$ & $1321 \cdot 3$ & $418 \cdot 4,1743 \cdot 5$ & $5 \cdot 0$ & $0.0,20 \cdot 0$ & $0 \cdot 0$ & $0.0,0.8$ & 0.0 & $0.0,0.0$ & $9 \cdot 6$ & $1 \cdot 5,30 \cdot 0$ & $5 \cdot 2$ & $3 \cdot 0,10 \cdot 3$ & $325 \cdot 0$ & $47 \cdot 2,700 \cdot 0$ \\
\hline All packaged foods ( $n$ 3459) & 1307.5 & $385 \cdot 3,1700 \cdot 0$ & $4 \cdot 1$ & $0.0,19 \cdot 4$ & $10 \cdot 0$ & $8 \cdot 3,10 \cdot 6$ & 0.0 & $0.0,0.0$ & $7 \cdot 3$ & $0 \cdot 7,26 \cdot 3$ & $5 \cdot 2$ & $3 \cdot 0,10 \cdot 3$ & $275 \cdot 0$ & $33 \cdot 3,642 \cdot 9$ \\
\hline
\end{tabular}

IQR, Interquartile range (percentile 25, percentile 75 ).

*Percentages are the proportion of packaged food with nutrition declarations by each food group classification.

†Food groups classification are based on the WHO/European nutrient profile model ${ }^{(15)}$

†Level of processing: Not processed/minimally processed, culinary ingredients, processed foods and ultra-processed food groups were classified according to the NOVA food classification system ${ }^{(22,23}$. 

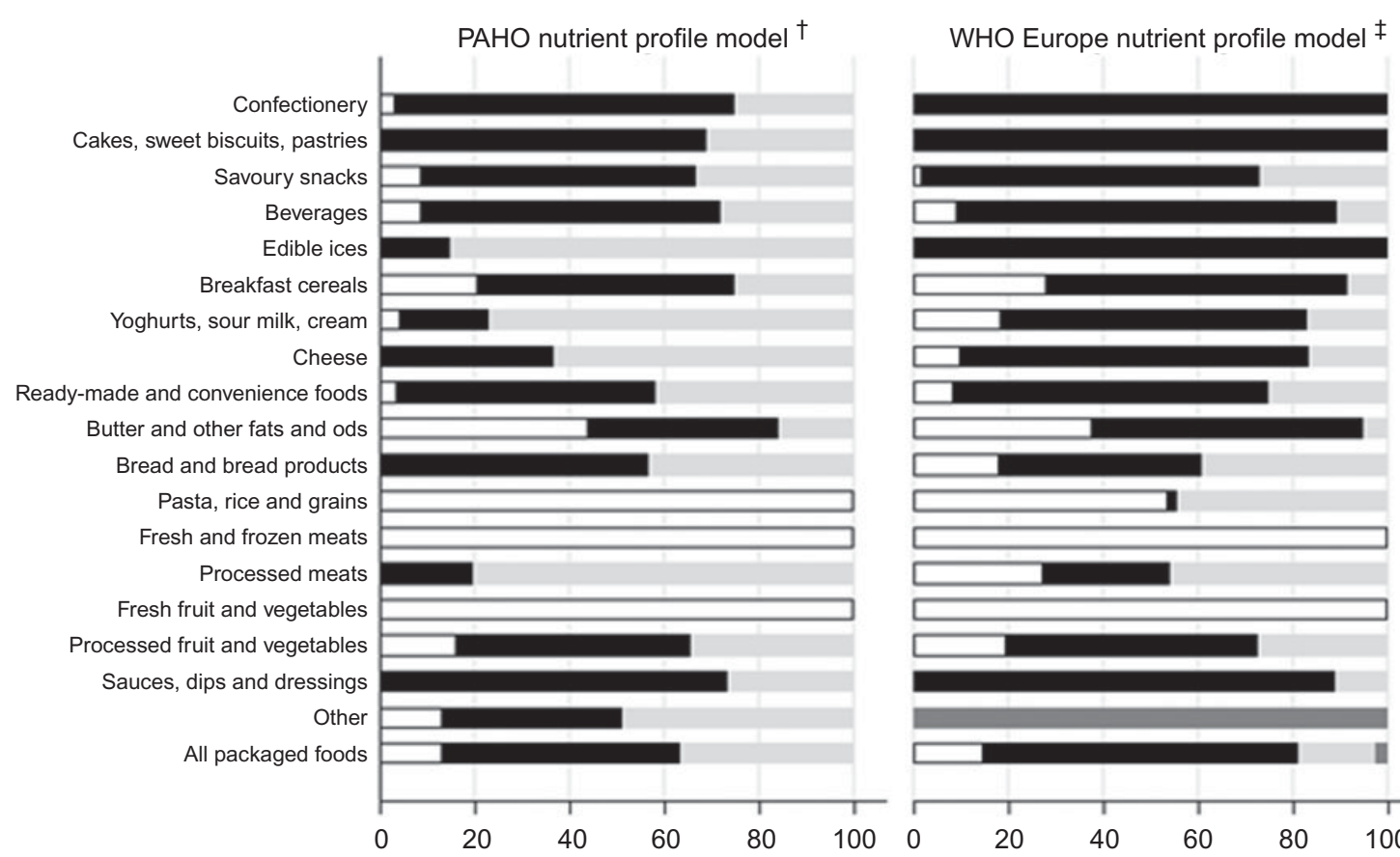

Fig. 2 Proportion of pre-packaged foods available in Guatemala that meet PAHO and WHO nutritional criteria. † Pan American Health Organization (PAHO): Products with excessive content of at least one nutrient were considered as not meeting the model's nutritional criteria using the following thresholds: $30 \%$ of total energy; saturated fats (SF): $10 \%$ of total energy; trans-fats: $1 \%$ of total energy; Na: $1 \mathrm{mg}$ per energy; added sugars (AS): $10 \%$ of total energy and non-sugar sweeteners (NSS): any amount of artificial sweeteners. Free sugars were estimated with the method proposed by PAHO, based on total sugars and food group, taking into consideration if the products contain ingredients with natural sugars, such as fruit or milk ${ }^{(14)}$. $\ddagger$ WHO: Confectionery, energy bars, cakes and sweets, juices, energy drinks and edible ices 'do not meet nutritional criteria'. Fresh and frozen meat, poultry, fish, fruit, vegetables and legumes 'meet nutritional criteria'. For the other categories, specific thresholds were used for each food group per $100 \mathrm{~g}$. Breads: $2.5 \mathrm{~g}$ total fat (TF), $0 \mathrm{~g}$ AS, $0 \mathrm{~g}$ NSS. Other beverages: $0 \mathrm{~g} \mathrm{AS}, 0 \mathrm{~g}$ NSS. Breakfast cereals: $10 \mathrm{~g}$ TF, $15 \mathrm{~g}$ total sugars (TS) and $1.6 \mathrm{~g}$ salt. Yoghurts, sour milk and others: $2.5 \mathrm{~g} \mathrm{TF}, 2.0 \mathrm{~g} \mathrm{SF}, 10 \mathrm{~g} \mathrm{TS}, 0.2 \mathrm{~g}$ salt. Cheese: $20 \mathrm{~g}$ TF and $1.3 \mathrm{~g}$ salt. Ready-made and convenience foods: $10 \mathrm{~g} \mathrm{TF}, 4 \mathrm{~g} \mathrm{SF}, 10 \mathrm{~g} \mathrm{TS}, 1 \mathrm{~g}$ salt and $941.4 \mathrm{~kJ}$. Butter and oils: $20 \mathrm{~g} \mathrm{SF}$ and $1.3 \mathrm{~g}$ salt. Bread, bread products and crisp breads: $10 \mathrm{~g} \mathrm{TF}, 10 \mathrm{~g}$ TS and $1.2 \mathrm{~g}$ salt. Fresh or dried pasta, rice and grain: $10 \mathrm{~g} \mathrm{TF}, 10 \mathrm{~g}$ TS and $1.2 \mathrm{~g}$ salt. Processed meat, poultry and fish: $20 \mathrm{~g}$ TF and $1.7 \mathrm{~g}$ salt. Processed fruit, vegetables and legumes: $5 \mathrm{~g}$ TF, $10 \mathrm{~g} \mathrm{TS}, 0 \mathrm{~g}$ AS and $1 \mathrm{~g}$ salt. Sauces, dips and dressings: $10 \mathrm{~g} \mathrm{TF}, 0 \mathrm{~g}$ AS and $1 \mathrm{~g}$ salt ${ }^{(15)}$. $\square$, Meets nutritional criteria; $\mathbf{a}$, missing information; $\ldots$, does not meet nutritional criteria; n, model not applicable

had less information than imported ones, probably because foreign manufacturers also sell to countries with stronger regulations. This finding was similar to what has been described in India ${ }^{(30)}$.

We also found that processed and ultra-processed products containing excessive quantities of nutrients related to NCD and cancer dominate the pre-packaged food offer in Guatemala ${ }^{(31,32)}$. This was consistent with findings in other countries ${ }^{(8,33)}$, showing that this is a widespread phenomenon. For example, in Colombia, $80 \%$ of products did not meet nutritional criteria of the PAHO model ${ }^{(34)}$. This proportion was even higher in Canada, Mexico and Uruguay with 93, 97 and 100\%, respectively ${ }^{(35-37)}$. In the EU and Canada, only 34 and $11.8 \%$ of products met WHO criteria ${ }^{(36,38)}$.

Insufficient nutrient information in packages has several consequences. For instance, the implementation of policies based on nutrient profiling (e.g. front-of-pack (FoP) food label systems, determining which products would be allowed to bear nutritional claim and limiting marketing to children) would be difficult with insufficient data. It is also concerning because labels are the most important source of nutritional information available to consumers ${ }^{(11)}$. They have been shown to influence food choices and to promote healthier diets ${ }^{(11,12)}$. However, use and understanding of labelling are low in developing countries ${ }^{(39)}$.

Changes to the labelling system have been proposed to address this problem. Countries like Chile Ecuador have implemented FoP food label systems, which are easy to understand, with specific messages to alert consumers about levels of nutrient related to NCD. The FoP warning label system in Chile also serves as a regulatory instrument to restrict marketing to children and to regulate the type of food products permitted within public schools ${ }^{(40,41)}$. An evidence-based FoP food label system and similar strategy in Guatemala would require mandatory declarations.

To our knowledge, this is the first study to assess the completeness of nutrition declarations and to evaluate the quality of pre-packaged food products in Guatemala with global nutrient profiling systems. Strengths of the study include the use of international nutrient profiling 
Table 3 Proportion of pre-packaged foods not meeting nutritional criteria according to the Pan American Health Association (PAHO)* nutrient profile model

\begin{tabular}{|c|c|c|c|c|c|c|c|c|c|c|}
\hline \multirow[b]{2}{*}{ Classification } & \multicolumn{6}{|c|}{$\mathrm{CN}(\%)$} & \multirow[b]{2}{*}{$\begin{array}{c}0 \\
\mathrm{CN}\end{array}$} & \multirow[b]{2}{*}{$\begin{array}{l}\text { At least } \\
\text { one } \mathrm{CN}\end{array}$} & \multirow[b]{2}{*}{$\begin{array}{l}1-2 \\
\mathrm{CN}\end{array}$} & \multirow[b]{2}{*}{$\begin{array}{l}3-4 \\
\mathrm{CN}\end{array}$} \\
\hline & $\begin{array}{l}\text { Total } \\
\text { fats }\end{array}$ & $\begin{array}{l}\text { Saturated } \\
\text { fats }\end{array}$ & Trans-fats & $\begin{array}{l}\text { Free } \\
\text { sugars }\end{array}$ & $\begin{array}{l}\text { Non-sugar } \\
\text { Sweeteners }\end{array}$ & $\mathrm{Na}$ & & & & \\
\hline \multicolumn{11}{|l|}{ By food group $†$} \\
\hline Confectionery (n 278) & 39.2 & 34.9 & 2.9 & $91 \cdot 7$ & 24.8 & $11 \cdot 1$ & 0.7 & $99 \cdot 3$ & $60 \cdot 8$ & 38.5 \\
\hline $\begin{array}{l}\text { Cakes, sweet biscuits and pastries } \\
(n 174)\end{array}$ & $62 \cdot 1$ & $66 \cdot 1$ & $7 \cdot 5$ & $74 \cdot 7$ & $9 \cdot 2$ & $34 \cdot 4$ & $1 \cdot 2$ & $98 \cdot 9$ & $42 \cdot 0$ & $57 \cdot 0$ \\
\hline Savoury snacks ( $n$ 169) & $89 \cdot 4$ & $58 \cdot 6$ & 0.0 & $7 \cdot 1$ & 0.0 & 61.5 & $1 \cdot 2$ & $98 \cdot 8$ & $56 \cdot 8$ & $42 \cdot 0$ \\
\hline Beverages ( $n 331)$ & $10 \cdot 6$ & $7 \cdot 6$ & 0.6 & 90.9 & $35 \cdot 7$ & 27.5 & 0.6 & $99 \cdot 4$ & $84 \cdot 3$ & $15 \cdot 1$ \\
\hline Edible ices $(n 7)$ & $85 \cdot 7$ & $85 \cdot 7$ & 0.0 & 100 & 0.0 & 0.0 & 0.0 & $100 \cdot 0$ & $14 \cdot 3$ & $85 \cdot 7$ \\
\hline Breakfast cereals ( $n$ 105) & 1.0 & $4 \cdot 8$ & 0.0 & 88.6 & 7.6 & $60 \cdot 0$ & $6 \cdot 7$ & $99 \cdot 3$ & $85 \cdot 7$ & $7 \cdot 6$ \\
\hline Yoghurts, cream ( $n$ 27) & $66 \cdot 7$ & $85 \cdot 2$ & 7.4 & $55 \cdot 6$ & 0.0 & $11 \cdot 1$ & $7 \cdot 4$ & $92 \cdot 6$ & 51.9 & $40 \cdot 7$ \\
\hline Cheese $(n 65)$ & $98 \cdot 5$ & $95 \cdot 4$ & $9 \cdot 2$ & 0.0 & 0.0 & $95 \cdot 4$ & 0.0 & $100 \cdot 0$ & $6 \cdot 1$ & 93.9 \\
\hline $\begin{array}{l}\text { Ready-made and convenience } \\
\text { foods ( } n 88)\end{array}$ & $46 \cdot 6$ & $40 \cdot 9$ & 0.0 & $28 \cdot 4$ & 0.0 & $88 \cdot 6$ & $6 \cdot 8$ & $94 \cdot 2$ & $58 \cdot 0$ & $36 \cdot 2$ \\
\hline $\begin{array}{l}\text { Butter and other fats and oils } \\
(n 44)\end{array}$ & $100 \cdot 0$ & $84 \cdot 1$ & $6 \cdot 8$ & $9 \cdot 1$ & 0.0 & $68 \cdot 2$ & 0.0 & $100 \cdot 0$ & $27 \cdot 3$ & $72 \cdot 7$ \\
\hline $\begin{array}{l}\text { Bread, bread products and crisp } \\
\text { breads ( } n \text { 59) }\end{array}$ & $13 \cdot 6$ & $17 \cdot 0$ & 0.0 & $18 \cdot 6$ & 0.0 & $93 \cdot 2$ & $1 \cdot 7$ & $98 \cdot 3$ & $84 \cdot 8$ & $13 \cdot 6$ \\
\hline $\begin{array}{l}\text { Processed meat, poultry, fish } \\
\quad(n 50)\end{array}$ & $78 \cdot 0$ & $44 \cdot 0$ & 0.0 & $2 \cdot 0$ & 0.0 & $100 \cdot 0$ & 0.0 & $100 \cdot 0$ & $56 \cdot 0$ & $44 \cdot 0$ \\
\hline $\begin{array}{l}\text { Processed fruit, vegetables and } \\
\text { legumes }(n 148)\end{array}$ & $17 \cdot 6$ & $2 \cdot 7$ & 0.0 & $45 \cdot 3$ & $5 \cdot 4$ & $45 \cdot 3$ & $10 \cdot 1$ & 89.9 & $83 \cdot 1$ & $6 \cdot 8$ \\
\hline $\begin{array}{l}\text { Sauces, dips and dressings } \\
\quad(n 189)\end{array}$ & $42 \cdot 3$ & $29 \cdot 6$ & 0.5 & $69 \cdot 8$ & 1.6 & $94 \cdot 1$ & 0.0 & $100 \cdot 0$ & $62 \cdot 4$ & $37 \cdot 6$ \\
\hline Other ( $n$ 35) & 0.4 & $5 \cdot 7$ & 0.0 & $48 \cdot 6$ & 0.0 & $82 \cdot 7$ & $2 \cdot 9$ & $97 \cdot 1$ & $77 \cdot 1$ & $20 \cdot 0$ \\
\hline \multicolumn{11}{|l|}{ By processing degreeł } \\
\hline Processed ( $n$ 112) & 33.9 & $19 \cdot 6$ & 0.0 & $28 \cdot 6$ & 0.0 & $66 \cdot 1$ & $9 \cdot 8$ & $90 \cdot 2$ & 69.7 & 20.5 \\
\hline Ultra-processed ( $n$ 1657) & $42 \cdot 4$ & 34.8 & $2 \cdot 1$ & $62 \cdot 6$ & 13.4 & 49.9 & 1.8 & 98.2 & 63.8 & 34.4 \\
\hline $\begin{array}{l}\text { All processed and ultra-processed } \\
\text { products }(n 1769) \ddagger\end{array}$ & $41 \cdot 8$ & 33.9 & $2 \cdot 0$ & 60.5 & $12 \cdot 6$ & $50 \cdot 9$ & $2 \cdot 2$ & $97 \cdot 8$ & $64 \cdot 2$ & 33.6 \\
\hline
\end{tabular}

CN, critical nutrient.

*PAHO: Products with excessive content of at least one nutrient were considered as not meeting the model's nutritional criteria using the following thresholds: $30 \%$ of total energy; saturated fats: $10 \%$ of total energy; trans-fats: $1 \%$ of total energy; Na: $1 \mathrm{mg}$ per energy; added sugars: $10 \%$ of total energy; sweeteners: any amount of artificial sweeteners. Free sugars were estimated with the method proposed by PAHO, based on total sugars and food group, taking into consideration if the products contain ingredients with natural sugar, such as fruit or milk(14).

†Food groups classification based on the WHO/European nutrient profile model ${ }^{(15)}$.

†Processing degree: processed foods and ultra-processed food groups were classified according to the NOVA food classification system ${ }^{(22,23)}$. Only processed/ ultra-processed products with declaration of necessary critical nutrients were included.

systems, a systematic methodology to classify products and a large sample size of food products commonly offered in Guatemala.

Our study did feature several limitations. First, we only sampled products in supermarkets and not in other food retailers such as convenience stores. In 2011, close to one quarter of groceries in the country were purchased in supermarkets. Urbanisation increases this proportion ${ }^{(20)}$. That said, most of the leading brands are sold in both supermarkets and convenience stores and nutrient composition is likely to be the same regardless of the outlet. We excluded unpackaged foods, including fresh fruits and vegetables, which tend to be healthier options. Therefore, our sample might not be representative of Guatemala's complete food offer. However, most foods available in supermarkets are pre-packaged, and its consumption is increasing. The fact that we could not obtain permission to photograph products in Walmart is also a limitation of the study. However, it is likely the most consumed products were also available in the other surveyed supermarkets. In addition, the purchase of Walmart's private-label brands minimised the number of products not evaluated. Another limitation is the fact that some of the products photographed in 2015 might no longer be on the market. However, we do not anticipate major changes in formulations to have happened in this period.

In conclusion, our study revealed that pre-packaged food products in Guatemalan supermarkets lack important nutritional information and have poor nutritional quality. There is an urgent need for regulation of critical nutrients declaration. Stronger regulations accompanied by compliance monitoring by strengthened governmental agencies have the potential to influence food choices. It is necessary to study the most effective way to deliver information to consumers, such as a FoP warning label system, to impact behaviour and allow informed selections that may lead to product reformulation and healthier food environments. 
Table 4 Proportion of ultra-processed and processed pre-packaged not meeting nutritional criteria according to WHOEurope nutrient profiling system*

\begin{tabular}{|c|c|c|c|c|c|c|c|}
\hline Classification & TF & SF & TS & AS & NSS & Salt & $\begin{array}{l}\text { Did not meet } \\
\text { nutritional criteria }\end{array}$ \\
\hline \multicolumn{8}{|l|}{ By food groupt } \\
\hline Confectionery ( $n$ 376) & & & & & & & $100 \cdot 0$ \\
\hline Cakes, sweet biscuits and pastries ( $n$ 253) & & & & & & & $100 \cdot 0$ \\
\hline Savoury snacks ( $n$ 204) & & & & $50 \cdot 0$ & & $96 \cdot 1$ & 98.0 \\
\hline Juices ( $n$ 10) & & & & & & & 100 \\
\hline Milk drinks ( $n$ 93) & $45 \cdot 6$ & & & $67 \cdot 7$ & $11 \cdot 2$ & & $88 \cdot 2$ \\
\hline Energy drinks ( $n$ 17) & & & & & & & 100 \\
\hline Other beverages ( $n$ 302) & & & & $88 \cdot 7$ & $36 \cdot 7$ & & 97.7 \\
\hline Edible ices ( $n 47)$ & & & & & & & 100 \\
\hline Breakfast cereals ( $n$ 141) & 9.9 & & $75 \cdot 9$ & & & 8.5 & $81 \cdot 6$ \\
\hline Yoghurts, cream ( $n$ 110) & 34.5 & $23 \cdot 6$ & 63.6 & & & & $78 \cdot 2$ \\
\hline Cheese $(n 14)$ & $64 \cdot 6$ & & & & & $76 \cdot 9$ & $87 \cdot 8$ \\
\hline Ready-made and convenience foods ( $n 113$ ) & $38 \cdot 1$ & $35 \cdot 4$ & $9 \cdot 7$ & & & $78 \cdot 8$ & 88.5 \\
\hline Butter and other fats and oils ( $n$ 62) & & $59 \cdot 7$ & & & & 69.4 & $85 \cdot 5$ \\
\hline Bread, bread products and crisp breads ( $n 63$ ) & $14 \cdot 3$ & & 9.5 & & & $58 \cdot 7$ & $69 \cdot 8$ \\
\hline Processed meat, poultry, fish ( $n$ 141) & $15 \cdot 6$ & & & & & $46 \cdot 1$ & 48.9 \\
\hline Processed fruit, vegetables and legumes ( $n$ 189) & $19 \cdot 6$ & & 35.9 & $40 \cdot 7$ & & 31.22 & $74 \cdot 0$ \\
\hline Sauces, dips and dressings ( $n$ 229) & 31.4 & & & $76 \cdot 4$ & & 84.7 & $99 \cdot 6$ \\
\hline \multicolumn{8}{|l|}{ By processing degreeł } \\
\hline Processed ( $n$ 181) & & & & & & & $65 \cdot 75$ \\
\hline Ultra-processed ( $n$ 2316) & & & & & & & 91.75 \\
\hline $\begin{array}{l}\text { All processed and ultra-processed products } \\
(n \text { 2497) } \ddagger\end{array}$ & & & & & & & $89 \cdot 87$ \\
\hline
\end{tabular}

TF, total fat; SF, saturated fats; TS, total sugars; AS, added sugars; NSS, non-sugar sweeteners.

*WHO: Confectionery, energy bars, cakes and sweets, juices, energy drinks, and edible ices 'do not meet nutritional criteria'. Fresh and frozen meat, poultry, fish, fruit, vegetables and legumes 'meet nutritional criteria'. For the other categories, specific thresholds were used for each food group per $100 \mathrm{~g}$. Breads: $2.5 \mathrm{~g}$ TF, $0 \mathrm{~g} \mathrm{AS}, 0 \mathrm{~g}$ NSS. Other beverages: $0 \mathrm{~g} \mathrm{AS}, 0 \mathrm{~g}$ NSS. Breakfast cereals: $10 \mathrm{~g} \mathrm{TF}, 15 \mathrm{~g} \mathrm{TS}$ and $1.6 \mathrm{~g}$ salt. Yoghurts, sour milk and others: $2.5 \mathrm{~g} \mathrm{TF}, 2.0 \mathrm{~g} \mathrm{SF}, 10 \mathrm{~g} \mathrm{TS}, 0.2 \mathrm{~g}$ salt. Cheese: $20 \mathrm{~g} \mathrm{TF}$ and $1.3 \mathrm{~g}$ salt. Ready-made and convenience foods: $10 \mathrm{~g} \mathrm{TF}, 4 \mathrm{~g} \mathrm{SF}, 10 \mathrm{~g} \mathrm{TS}, 1 \mathrm{~g}$ salt and $941.4 \mathrm{~kJ}$. Butter and oils: $20 \mathrm{~g}$ SF and $1.3 \mathrm{~g}$ salt. Bread, bread products and crisp breads: $10 \mathrm{~g}$ TF, $10 \mathrm{~g}$ TS, $1.2 \mathrm{~g}$ salt. Fresh or dried pasta, rice and grain: $10 \mathrm{~g} \mathrm{TF}, 10 \mathrm{~g} \mathrm{TS}, 1.2 \mathrm{~g}$ salt. Processed meat, poultry and fish: $20 \mathrm{~g}$ TF and $1.7 \mathrm{~g}$ salt. Processed fruit, vegetables and legumes: $5 \mathrm{~g}$ TF, $10 \mathrm{~g}$ TS, $0 \mathrm{~g}$ AS and $1 \mathrm{~g}$ salt. Sauces, dips and dressings: $10 \mathrm{~g} \mathrm{TF}, 0 \mathrm{~g} \mathrm{AS}$ and $1 \mathrm{~g}$ salt. ${ }^{(15)}$. tFood groups classification based on the WHO/European nutrient profile model ${ }^{(15)}$.

$\ddagger$ Processing degree: processed foods and ultra-processed food groups were classified according to the NOVA food classification system ${ }^{(22,23)}$. Only processed/ultra-processed products with declaration of necessary critical nutrients were included.

\section{Acknowledgements}

Acknowledgements: The authors are thankful for the financial support provided by the International Development Research Centre (IDRC). They also thank CIIPEC staff who collaborated with data collection and Dina Roche for assistance with data management. Financial support: This study was supported by a research training grant from the IDRC-CRDI (grant number \#107213001). The IDRC had no role in the design, analysis or writing of this article. Conflict of interest: All authors declare that there is no conflict of interest regarding the publication of this article. S.V. is a Deputy Editor for Public Health Nutrition. Authorship: All authors participated in the study design; A.A.C. acquired, analysed and interpreted the data; A.A.C. drafted the manuscript; M.F.K.L. led the data analysis plan and manuscript writing. S.V., M.R.Z. and M.F.K.L. assisted in the analysis and interpretation of the results and provided critical intellectual feedback to help revise the manuscript. Ethics of buman subject participation: This study did not include human subjects.

\section{References}

1. World Health Organization (2015) NCD Mortality and Morbidity. http://www.who.int/gho/ncd/mortality_morbidity/ en/ (accessed August 2017).

2. Popkin BM, Adair LS \& Ng SW (2012) Global nutrition transition and the pandemic of obesity in developing countries. Nutr Rev 70, 3-21.

3. World Health Organization (2014) Global status report on noncommunicable diseases 2014, 176.

4. Ministry of Public Health and Social Assistance (MSPAS) (2015) Analysis of the Epidemiological situation of noncommunicable diseases in Guatemala 2015. Guatemala.

5. Ramirez-Zea M, Kroker-Lobos MF, Close-Fernandez R et al. (2014) The double burden of malnutrition in indigenous and nonindigenous. Am J Clin Nutr 100, 1644-1651.

6. Ng M, Fleming T, Robinson M et al. (2014) Global, regional, and national prevalence of overweight and obesity in children and adults during 1980-2013: a systematic analysis for the Global Burden of Disease Study 2013. Lancet 384, 766-781.

7. Forouzanfar MH, Afshin A, Alexander LT et al. (2016) Global, regional, and national comparative risk assessment of 79 behavioural, environmental and occupational, and metabolic risks or clusters of risks, 1990-2015: a systematic analysis for the Global Burden of Disease Study 2015. Lancet 388, $1659-1724$. 
8. Monteiro CA, Moubarac JC, Cannon G et al. (2013) Ultraprocessed products are becoming dominant in the global food system. Obes Rev 14, 21-28.

9. Pan American Health Organization (2015) Ultra-processed foods and beverages in Latin America: trends, effect on obesity and implications for public policies. http://iris. paho.org/xmlui/bitstream/handle/123456789/7698/9789275 318645_esp.pdf?sequence $=5$ (accessed August 2017).

10. Swinburn B, Sacks G, Vandevijvere S et al. (2013) INFORMAS (International Network for Food and Obesity/noncommunicable diseases Research, Monitoring and Action Support): overview and key principles. Obes Rev 14, 1-12.

11. Campos S, Doxey J \& Hammond D (2011) Nutrition labels on pre-packaged foods: a systematic review. Public Health Nutr 14, 1496-1506.

12. Cowburn G \& Stockley L (2005) Consumer understanding and use of nutrition labeling: a systematic review. Public Heal Nutr 8, 21-28. http://www.journals.cambridge.org/ abstract_S1368980005000054 (accessed October 2019).

13. Council of Ministers of Central American Economic Integration (2012) Central American Technical Regulation. Nutritional labeling of pre-packaged food products for human consumption for the population from 3 years of age, pp. 1-45. http://www.mineco.gob.gt/sites/default/ files/pdfs/res_280-2012_rtca_etiquetado_preenvasados.pdf (accessed August 2017).

14. Pan American Health Organization (2016) Nutrient Profile Model, 32 p. Washington, DC. http://iris.paho.org/xmlui/ bitstream/handle/123456789/18621/9789275118733_eng.pdf (accessed October 2019).

15. WHO Regional Office for Europe (2015) WHO Regional Office for Europe nutrient profile model. Copenhagen.

16. Tetens I, Oberdörfer R, Madsen C et al. (2007) Nutritional characterisation of foods: science-based approach to nutrient profiling - summary report of an ILSI Europe workshop held in April 2006. Eur J Nutr 46, Suppl. 2, 4-14.

17. Lobstein T \& Davies S (2009) Defining and labelling 'healthy' and 'unhealthy' food. Public Health Nutr 12, 331-340. http://journals.cambridge.org/abstract_S1368980008002541 (accessed October 2019).

18. Dunford $\mathrm{E}$, Webster J, Metzler AB et al. (2012) International collaborative project to compare and monitor the nutritional composition of processed foods. Eur J Prev Cardiol 19 1326-1332. http://www.ncbi.nlm.nih.gov/pubmed/21971487 (accessed October 2019).

19. Dunford E (2013) Progress with a global branded food composition database. Food Chem 140, 451-457. doi: 10.1016/j. foodchem.2012.10.065.

20. Euromonitor International (2016) Grocery Retailers in Guatemala. Euromonitor International. http://www.euro monitor.com/grocery-retailers-in-guatemala/report (accessed May 2016).

21. Harris PA, Taylor R, Thielke Ret al. (2009) Research electronic data capture (REDCap) - a metadata-driven methodology and workflow process for providing translational research informatics support. J Biomed Inform 42, 377-381. doi: 10.1016/ j.jbi.2008.08.010.

22. Monteiro CA, Cannon G \& Levy RB (2016) NOVA. The star shines bright. World Nutr 7, 28-38.

23. Monteiro C, Levy R, Claro R et al. (2010) A new classification of foods based on the extent and purpose of their processing. Cad Saude Publica 26, 2039-2049.

24. Joint FAO/WHO Codex Alimentarius Commission (2017) Codex Alimentarius Guidelines on Nutrition Labelling. CAC/ GL 2-1985, p. 10. http://www.fao.org/fao-who-codexalim entarius/sh-proxy/en/?lnk=1\&url=https\%253A\%252F\%252Fwork space.fao.org\%252Fsites $\% 252$ Fcodex $\% 252$ FStandards\%252FCAC \%2BGL\%2B2-1985\%252FCXG_002e.pdf (accessed October 2019).
25. Yang Q, Zhang Z, Gregg EW et al. (2014) Added sugar intake and cardiovascular diseases mortality among US adults. JAMA Intern Med 174, 516-524.

26. Mozaffarian Dariush KBM, Ascherio Alberto SMJ, Willett WC (2006) Trans fatty acids and cardiovascular disease. $N$ Engl J Med 354, 13. http://www.nejm.org/doi/pdf/10. 1056/NEJMra054035 (accessed October 2019).

27. Te Morenga LA, Howatson AJ, Jones RM et al. (2014) Dietary sugars and cardiometabolic risk: systematic review and metaanalyses of randomized controlled trials of the effects on blood pressure and lipids. Am J Clin Nutr 100, 65-79.

28. Tee ES, Tamin S, Ilyas R et al. (2002) Current status of nutrition labelling and claims in South-East Asian region: are we in harmony? Asia Pac J Clin Nutr 11, 80-86.

29. Huang L, Neal B, Dunford E et al. (2016) Completeness of nutrient declarations and the average nutritional composition of pre-packaged foods in Beijing, China. Prev Med Rep 4, 397-403. doi: 10.1016/j.pmedr.2016.08.002.

30. Dunford EK, Guggilla RK, Ratneswaran A et al. (2015) The adherence of packaged food products in Hyderabad, India with nutritional labelling guidelines. Asia Pac J Clin Nutr 24, 540-545.

31. Fiolet T, Srour B, Sellem L et al. (2018) Consumption of ultraprocessed foods and cancer risk: results from NutriNet-Santé prospective cohort. BMJ 360, k322. http://www.ncbi.nlm. nih.gov/pubmed/29444771 (accessed October 2019).

32. Costa CS, Del-Ponte B, Assunção MCF et al. (2018) Consumption of ultra-processed foods and body fat during childhood and adolescence: a systematic review. Public Health Nutr 21, 148-159. http://www.ncbi.nlm.nih.gov/ pubmed/28676132 (accessed October 2019).

33. Luiten CM, Steenhuis IH, Eyles H et al. (2015) Ultra-processed foods have the worst nutrient profile, yet they are the most available packaged products in a sample of New Zealand supermarkets. Public Health Nutr 19, 1-9. http:// www.ncbi.nlm.nih.gov/pubmed/26222226 (accessed October 2019).

34. Mora-Plazas M, Gómez LF, Miles DR et al. (2019) Nutrition quality of packaged foods in Bogotá, Colombia: a comparison of two nutrient profile models. Nutrients 11, $1-13$.

35. Giménez A, Saldamando L de, Curutchet MR et al. (2017) Package design and nutritional profile of foods targeted at children in supermarkets in Montevideo, Uruguay. Cad Saude Publica 33, e00032116.

36. Elliott C \& Scime NV (2019) Nutrient profiling and childtargeted supermarket foods: assessing a 'made in Canada' policy approach. Int J Environ Res Public Health 16, 1-12.

37. Contreras-Manzano A, Jáuregui A, Velasco-Bernal A et al. (2018) Comparative analysis of the classification of food products in the Mexican market according to seven different nutrient profiling systems. Nutrients 10, 1-17.

38. Bonsmann SSg, Robinson M, Wollgast J et al. (2019) The ineligibility of food products from across the EU for marketing to children according to two EU-level nutrient profile models. PLoS One 14, 1-17.

39. Mandle J, Tugendhaft A, Michalow J et al. (2015) Nutrition labelling: a review of research on consumer and industry response in the global South. Glob Health Action 8, 1-10.

40. Pérez-Escamilla R, Lutter CK, Rabadan-Diehl C et al. (2017) Prevention of childhood obesity and food policies in Latin America: from research to practice. Obes Rev 18, 28-38. doi: 10.1111/obr.12574.

41. Orozco F, Ochoa D, Muquinche M et al. (2016) Awareness, comprehension, and use of newly mandated nutrition labels among Mestiza and Indigenous Ecuadorian women in the Central Andes Region of Ecuador. Food Nutr Bull 38, 037957211668473. http://journals.sagepub.com/doi/10. 1177/0379572116684730 (accessed October 2019). 